Bull. Egypt. Soc. Physiol. Sci. Vol. (42, Issue (1), 27-38

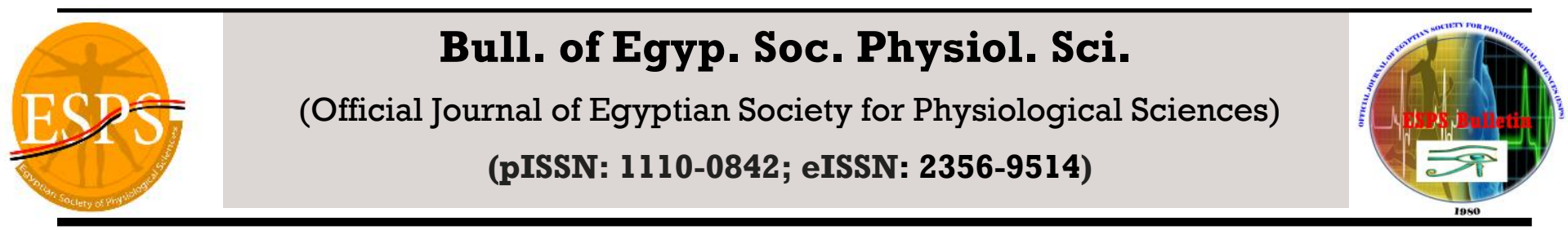

\title{
Correlation between serum 25-hydroxyvitamin D levels and VEP and OCT in patients with primary open-angle glaucoma
}

\author{
Fahmy, Hassan L. ; Ali, Anwar M. †; Sayed, Sally A. ${ }^{\S}$; Anwar, Mohammed* \\ *Department of Ophthalmology, Faculty of Medicine, Assiut University Hospital, Assiut, Egypt \\ ${ }^{\dagger}$ Department of Neurology, Faculty of Medicine, Assiut University Hospital, Assiut, Egypt \\ ${ }^{\S}$ Department of Physiology, Faculty of Medicine, Assiut University, Assiut, Egypt
}

Submit Date: 7 April 2021

Revise Date: 7 April 2021

Accept Date :4 May 2021

Keywords

- Primary openangle glaucoma

- Vitamin D

- IOP

- OCT

- VEP

\section{Abstract}

Purpose: Primary open-angle glaucoma has been identified as the most common type of glaucoma. Elevated intraocular pressure, advanced age, positive family history, and African ancestry are well-known risk factors for primary open-angle glaucoma. Vitamin $\mathrm{D}$ is a known vital contributor to health. Thus, this present study aimed to clarify the neurophysiological role of vitamin D deficiency in primary open-angle glaucoma and to examine the correlation between vitamin D deficiency and the structural changes associated with primary open-angle glaucoma. Patients and Methods: All patients participating in this study underwent the best visual acuity examination. In addition, intraocular pressure, optical coherence tomography, and visual evoked potentials were measured.Results: As per our findings, it was determined that vitamin D negatively correlated with intraocular pressure in patients less than 45 years of age (r-value: -0.803 ; p-value: 0.002). Vitamin D also negatively correlated with age when optical coherence tomography was >94 $\mu \mathrm{m}$ (r-value: -0.526 ; p-value: 0.044). Vitamin D negatively correlated with intraocular pressure when visual evoked potential latency was <100 msec (r-value: p-value: 0.036). Conclusion: We can conclude that vitamin $\mathrm{D}$ has an ameliorating effect on intraocular pressure when optic nerve conduction velocity is normal, but once optic nerve function deteriorates, the vitamin D effect decreases.

Corresponding author: Sayed, Sally A. Department of Physiology, Faculty of Medicine, Assiut University, Assiut, Egypt. Email: sallyanw19@aun.edu.eg. Tel: +201026904036. Fax: 088-2332278-2080278. Postal address: 71515, Assiut University, Faculty of Medicine, Egypt, Medical Physiology Department 


\section{INTRODUCTION}

Glaucoma, which is a progressive optic neuropathy, has been identified as the leading cause of irreversible blindness worldwide [1]. Primary open-angle glaucoma (POAG) is the most common type of glaucoma. POAG is often characterized by gradual visual field loss, which is typically asymptomatic at the early stages and is often not detected until irreversible loss of the visual field transpires. Elevated intraocular pressure (IOP), advanced age, positive family history, and African ancestry are well-known risk factors for POAG [2].

Vitamin D is a hormone that affects not only bone metabolism, but also other systems [3]. Over the last couple of decades, research has shown that vitamin $\mathrm{D}$ is a multifunctional molecule and an essential contributor to health. Vitamin D deficiency is associated with osteoporosis, cardiovascular disease, diabetes, cancer, autoimmune diseases, and depression [4]. Vitamin $\mathrm{D}$ can also affect proliferation, cell differentiation, apoptosis, angiogenesis, immunity, and gene regulation [5]. Vitamin D can be obtained from food or through UVB-dependent vitamin D production in the skin. Vitamin D is rapidly hydroxylated in the liver to 25-hydroxyvitamin D (25OHD). This form is currently regarded as the best marker of vitamin D status [6,7].

Visual evoked potential (VEP) stimulation is used to diagnose glaucoma. It assesses the integrity of the visual pathways from the fovea toward the occipital cortex. VEP latency is used as a measure of early glaucomatous damage before retinal ganglion cell death occurs. Optic disk cupping and visual field loss are associated with the prolongation of VEP latency. Hence, VEP is used as a marker of reversible ganglion cell damage. VEP is our neurophysiological tool to examine the pathophysiology of progressive optic neuropathy in patients with POAG [8].

However, VEP measurements cannot replace an optical coherence tomography (OCT) examination of the optic nerve in patients with POAG. Thus, OCT is a widely used and proven imaging modality for the evaluation of POAG in daily practice. This imaging method gives qualitative and quantitative assessments of POAG. Associated structural changes in the optic nerve head, the retinal nerve fiber layer (RNFL), and ganglion cell layer (GCC) in the macular region are routinely diagnosed using OCT [9].

In this present study, we aim to clarify the neurophysiological role of vitamin D deficiency in POAG. OCT was used to study the correlation between vitamin $\mathrm{D}$ deficiency and the structural changes associated with POAG. In addition, the effects of vitamin D deficiency on VEP patterns in patients with POAG were examined.

\section{MATERIALS AND METHODS}

The Ethics Committee of the Faculty of Medicine (Assiut University) and Assiut University Hospital approved this study. In total, 41 patients with POAG were recruited from the Department of Ophthalmology, Assiut University Hospital, Assiut, Egypt. The procedure was discussed, and informed consent was obtained from all patients.

All patients participating in the study underwent the best corrected visual acuity (BCVA) examination, IOP measurements, and OCT. VEP 
was measured in all patients in an outpatient clinic. Serum blood samples were also collected for measurement of 25-hydroxycholecalciferol, which was performed in the Medical Physiology Department, Faculty of Medicine, Assiut University Hospital, Assiut, Egypt.

\section{Patient characteristics}

Both male and female patients with POAG from 40 to 70 years of age were included in this study. Patients below the age of 40 and above the age of 70 were excluded from the study. In addition, patients with mature cataracts and patients with diabetic or hypertensive retinopathies were excluded from analysis. All POAG patients were using at least one anti-glaucoma eye drop. Patients were classified according to age into three groups: below 45 years, 45-60 years, and above 60 years of age.

\section{Equipment}

All patients participating in the study were subjected to the best IOP measurement using a Tono-Pen AVIA handheld tonometer (TPA, Reichert Inc. NY, USA). This instrument utilizes an electronic micro strain gauge transducer and a digital microprocessor to generate objective digital measurements from changes in voltage utilizing the McKay-Mar principle to measure IOP. The instrument displays the average of 10 independent readings [10].

Patients with refractory errors wore eyeglasses. Every examination was performed with the patient sitting comfortably in an armchair under standard conditions at even temperatures in a darkened room. Fixation of gaze at the screen was controlled throughout the examination. The VEP recording was made using Nihon Kohden Neuropack 4equipment (made in Japan). Monocular full-field stimulation was performed using the pattern-reversal checkerboard. Each check subtended $37^{\prime}$ of the visual field. The contrast ratio of the checks was 0.80. Recording $\mathrm{AgCl}_{2}$ electrodes were located on $\mathrm{Oz}-\mathrm{Cz}$ with a grounding electrode on Fz, according to the 10-20 system. Electric impedance was $<5 \mathrm{kOhm}$. The rate of pattern reversal was $1 \mathrm{~Hz}$, and an average of 200 responses was recorded. The latencies of $\mathrm{N} 1, \mathrm{P} 1$, and N1-P1 amplitudes were taken into consideration. The average of each eye recording obtained from the same patient was used for the calculations. The pattern of VEP is represented by an initial negative peak at about $75 \mathrm{~ms}$ (N75), then a positive peak (P100) at about $100 \mathrm{~ms}$, followed by another negative peak at about $145 \mathrm{~ms}$ (N145) [11].

The Cirrus HD-OCT (software version 5.0) acquires images at a speed of 27,000 A-scans per $\mathrm{sec}$ at $5 \mu \mathrm{m}$ axial resolution in tissue. The Macular Cube $200 \times 200$ protocol was used to take measurements of macular thickness. This scan generates a cube of data by performing raster scanning in a $6 \times 6 \mathrm{~mm}$ square grid consisting of 200 frames of horizontal linear B-scans with 200 A-scan lines per B-scan. Meanwhile, the Optic Disk Cube $200 \times 200$ scan was used to obtain RNFL thickness measurements. Thickness data for the macular parameters were obtained using the manufacturer's prerelease segmentation software from an elliptical annulus centered on the fovea with an inner vertical radius of $0.5 \mathrm{~mm}$ and an outer vertical radius of $2 \mathrm{~mm}$, stretched horizontally by $20 \%$. The elliptical annulus was divided into six sectors, each subtending 60 degrees [12]. 
Blood samples were taken from the cubital fossa of the patients and controls. Blood samples $(5 \mathrm{ml})$ were collected and allowed to clot for at least 30 minutes. Then, the blood samples were centrifuged at 3,000 RPM for 5 min within 1 hour of collection for separation of serum. Estimations of vitamin D levels were based on the competitive inhibition ELISA technique. Microtiter wells were then coated with anti-vitamin D monoclonal antibody (mAb Anti-25-OH vitamin D). Patient sera and standards were added followed by extraction buffer in order to release vitamin $\mathrm{D}$ from its binding protein. After the first incubation and washing step, a constant amount of biotinylated 25-OH vitamin D and horseradish peroxidaseconjugated streptavidin were added simultaneously to the wells. The added reagents, which were in the complex form (biotinylated 25-OH vitamin D bound to streptavidin HRP), competed with the endogenous serum vitamin $\mathrm{D}$ for a limited number of binding sites on the coated anti-vitamin D antibodies. After incubation, the wells were washed to remove unbound reagents; thereafter, a solution of chromogen substrate was added and incubated for 15 minutes, resulting in the development of blue color. The color development was stopped with the addition of stop solution. The color changed to yellow and was measured spectrophotometrically at $450 \mathrm{~nm}$. The color intensity was proportional to the amount of biotinylated 25-hydroxy vitamin $\mathrm{D}$ and was inversely related to the amount of endogenous 25$\mathrm{OH}$ vitamin $\mathrm{D}$ in the test sample. In reference to a series of vitamin D standards assayed in the same way, the concentration of $25-\mathrm{OH}$ vitamin $\mathrm{D}$ in the unknown sample was quantified [13].

\section{Data analysis}

Data were entered into Statistical Package for the Social Sciences. Descriptive statistics used in this study included means, standard deviations, percentages, and frequencies of variables. Correlations between the vitamin D level and VEP and OCT were assessed using Pearson and Spearman correlation coefficients.

\section{RESULTS}

\section{Demographics and ocular characteristics}

The analyses included 82 eyes of 41 patients with POAG

Thirty seven men $(44.1 \%)$ and forty five women $55.9 \%$ )were enrolled in the study. The mean patient age was $54.5 \pm 15.86$ years. Patient demographics and clinical visual function variables are provided in Table 1 and Figure 1. Mean BCVA was $0.145 \pm 0.172$. The percentage of patients with controlled glaucoma was $54.4 \%$, while $45.6 \%$ of patients were determined to have uncontrolled glaucoma.

\section{Classification of patients with POAG according} to sex and age

Vitamin D levels and visual parameters are shown according to sex and age classifications in Table 2 . The vitamin D levels were $31 \pm 3.95 \mathrm{ng} / \mathrm{ml}$ in male patients with POAG, whereas for female patients, the vitamin D levels were found to be $30.5 \pm 1.98$ ng/ml. Further, vitamin D levels were $36.1 \pm 4.9$ $\mathrm{ng} / \mathrm{ml}$ in patients under the age of 45 years, $30.9 \pm$ $2.9 \mathrm{ng} / \mathrm{ml}$ in patients from 45 to 60 years, and 26.8 $\pm 3 \mathrm{ng} / \mathrm{ml}$ in patients above 60 years of age.

The VEP latency (P100) in male patients with POAG was $136.8 \pm 6.2 \mathrm{msec}$. In female patients, VEP latency was $124.4 \pm 5.4 \mathrm{msec}$. The VEP latency was $128.8 \pm 9.5 \mathrm{msec}$ in patients less than 
45 years of age, $126.9 \pm 5.7 \mathrm{msec}$ in patients aged from 45 to 60 years, and $136.8 \pm 7.3 \mathrm{msec}$ in patients above the age of 60 years. The VEP amplitude (N75-P100) in male patients with POAG was $0.79 \pm 0.33 \mu \mathrm{V}$, while the VEP amplitude in female patients was $1.7 \pm 0.79 \mu \mathrm{V}$. The VEP amplitudes were $0.21 \pm 0.21 \mu \mathrm{V}, 1.9 \pm$ $0.79 \mu \mathrm{V}$, and $0.61 \pm 0.46 \mu \mathrm{V}$ in patients less than 45 years, 45 to 60 years, and above 60 years of age, respectively.

The BCVA (nominator divided by denominator) in male patients with POAG was $0.13 \pm 0.03$ and in female patients $0.16 \pm 0.03$. The BCVAs were $0.13 \pm 0.05,0.17 \pm 0.03$, and $0.11 \pm 0.03$ in patients less than 45 years, 45 to 60 years, and above 60 years of age, respectively.

The IOP in male patients with POAG was $21.9 \pm$ $2.4 \mathrm{mmHg}$, while the IOP in female patients was $23.4 \pm 1.8 \mathrm{mmHg}$. The IOPs were $22.1 \pm 3.4$ $\mathrm{mmHg}, 24.3 \pm 2.07 \mathrm{mmHg}$, and $19.9 \pm 2.3 \mathrm{mmHg}$ in patients less than 45 years, 45 to 60 years, and above 60 years of age, respectively.

The OCT (RNFL thickness) in male patients with POAG was determined to be $49.6 \pm 7.8 \mu \mathrm{m}$, whereas the OCT in female patients was $53.4 \pm 6.8$ $\mu \mathrm{m}$. OCTs were $56.4 \pm 12 \mu \mathrm{m}, 51.3 \pm 7.3 \mu \mathrm{m}$, and $49.6 \pm 8.9 \mu \mathrm{m}$ in patients less than 45 years, 45 to 60 years, and above 60 years of age, respectively.

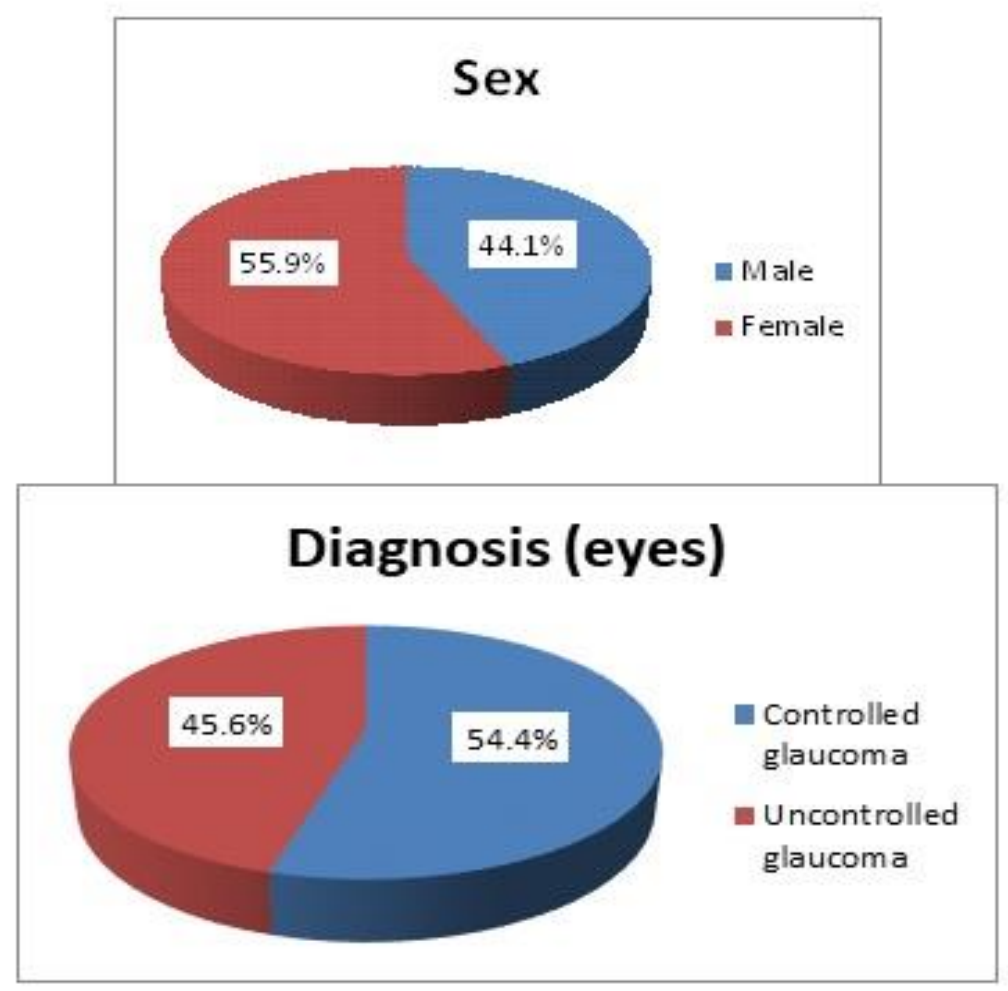

Figure 1: A represents male/female ratio in patients with POAG. B represents distribution of controlled and uncontrolled patients with POAG. 
Table 1: Demographic and biometric characteristics of the enrolled study sample

\begin{tabular}{|lc|}
\hline Variable & \\
\hline No. of eyes (patients) & $82(41)$ \\
Age, $\mathbf{y}$, Mean \pm SD & $54.5 \pm 15.86$ \\
Sex (M/F), No.(\%) & $37(44.1 \%) / 45(55.9 \%)$ \\
Best corrected Visual acuity, Mean \pm SD & $0.145 \pm 0.172$ \\
Diagnosis (eyes) & \\
$\quad$ Controlled glaucoma, No.(\%) & $44(54.4 \%)$ \\
$\quad$ Uncontrolled glaucoma, No.(\%) & $38(45.6 \%)$ \\
\hline
\end{tabular}

Table 2: Distribution of clinical visual parameters among glaucoma participants (VEP: Visual evoked potential; BCVA: Best corrected Visual Acuity; IOP: Intraocular pressure; OCT: Optical coherence tomography)

\begin{tabular}{|c|c|c|c|c|c|c|c|c|c|c|c|c|c|}
\hline \multirow[t]{2}{*}{ Variable } & \multirow[t]{2}{*}{$\mathbf{N}$} & \multicolumn{2}{|c|}{ Vitamin D } & \multicolumn{2}{|c|}{ VEP latency (P100) } & \multicolumn{2}{|c|}{$\begin{array}{c}\text { Amplitude (N75- } \\
\text { P100) }\end{array}$} & \multicolumn{2}{|c|}{ BCVA } & \multicolumn{2}{|c|}{ IOP } & \multicolumn{2}{|c|}{ OCT } \\
\hline & & $\begin{array}{c}\text { Mean } \pm S \\
\mathbf{E}\end{array}$ & $\begin{array}{c}95 \% \\
\text { CI }\end{array}$ & $\begin{array}{c}\text { Mean } \pm S \\
\mathbf{E}\end{array}$ & $95 \% \mathrm{CI}$ & $\begin{array}{c}\text { Mean } \pm \\
\text { SE }\end{array}$ & $95 \% \mathrm{CI}$ & $\begin{array}{c}\text { Mean } \pm \\
\text { SE }\end{array}$ & $\begin{array}{c}95 \% \\
\text { CI }\end{array}$ & $\begin{array}{c}\text { Mean } \pm \\
\text { SE }\end{array}$ & $\begin{array}{c}95 \% \\
\text { CI }\end{array}$ & $\begin{array}{c}\text { Mean } \pm \\
\text { SE }\end{array}$ & $\begin{array}{c}95 \% \\
\text { CI }\end{array}$ \\
\hline Sex & & & & & & & & & & & & & \\
\hline Male & 30 & $31 \pm 3.95$ & $\begin{array}{l}22.9- \\
39.1\end{array}$ & $136.8 \pm 6.2$ & $\begin{array}{l}124.1- \\
149.4\end{array}$ & $\begin{array}{c}0.79 \pm 0 \\
.33\end{array}$ & $0.13-1.6$ & $\begin{array}{l}0.13 \pm 0 \\
.03\end{array}$ & $\begin{array}{c}0.06- \\
0.2\end{array}$ & $\begin{array}{c}21.9 \pm 2 \\
.4\end{array}$ & $\begin{array}{l}16.9- \\
26.8\end{array}$ & $\begin{array}{c}49.6 \pm 7 \\
.8\end{array}$ & $\begin{array}{l}33.6- \\
65.5\end{array}$ \\
\hline Female & 38 & $30.5 \pm 1.98$ & $\begin{array}{l}26.5- \\
34.5\end{array}$ & $124.4 \pm 5.4$ & $\begin{array}{c}113.6- \\
135.2\end{array}$ & $\begin{array}{c}1.7 \pm 0 \\
79\end{array}$ & $0.9-3.3$ & $\begin{array}{c}0.16 \pm 0 \\
.03\end{array}$ & $\begin{array}{l}0.1- \\
0.21\end{array}$ & $\begin{array}{c}23.4 \pm 1 \\
.8\end{array}$ & $\begin{array}{l}19.8- \\
26.9\end{array}$ & $\begin{array}{c}53.4 \pm 6 \\
.8\end{array}$ & $\begin{array}{c}39.7- \\
67.1\end{array}$ \\
\hline Age & & & & & & & & & & & & & \\
\hline$<45 \mathrm{y}$ & 12 & $36.1 \pm 4.9$ & $\begin{array}{l}25.3- \\
46.8\end{array}$ & $128.8 \pm 9.5$ & $\begin{array}{c}107.9- \\
149.8\end{array}$ & $\begin{array}{l}0.21 \pm 0 \\
.21\end{array}$ & $\begin{array}{c}-0.25- \\
0.66\end{array}$ & $\begin{array}{l}0.13 \pm 0 \\
.05\end{array}$ & $\begin{array}{c}0.03- \\
0.23\end{array}$ & $\begin{array}{c}22.1 \pm 3 \\
.4\end{array}$ & $\begin{array}{l}14.5- \\
29.6\end{array}$ & $\begin{array}{c}56.4 \pm 1 \\
2\end{array}$ & $\begin{array}{l}29.9- \\
82.9\end{array}$ \\
\hline $\begin{array}{l}45 \text { to } \\
60 y\end{array}$ & 38 & $30.9 \pm 2.9$ & $\begin{array}{l}24.9- \\
36.9\end{array}$ & $126.9 \pm 5.7$ & $\begin{array}{l}115.3- \\
138.5\end{array}$ & $\begin{array}{c}1.9 \pm 0 . \\
79\end{array}$ & $0.36-3.6$ & $\begin{array}{c}0.17 \pm 0 \\
.03\end{array}$ & $\begin{array}{l}0.1- \\
0.23\end{array}$ & $\begin{array}{c}24.3 \pm 2 \\
.07\end{array}$ & $\begin{array}{l}20.1- \\
28.4\end{array}$ & $\begin{array}{c}51.3 \pm 7 \\
.3\end{array}$ & $\begin{array}{c}36.6- \\
65.9\end{array}$ \\
\hline$>60 y$ & 18 & $26.8 \pm 3$ & $\begin{array}{c}20.4- \\
33.1\end{array}$ & $136.8 \pm 7.3$ & $\begin{array}{c}121.4- \\
152.2\end{array}$ & $\begin{array}{l}0.61 \pm 0 \\
.46\end{array}$ & $\begin{array}{c}-0.35- \\
1.6\end{array}$ & $\begin{array}{c}0.11 \pm 0 \\
.03\end{array}$ & $\begin{array}{c}0.05- \\
0.18\end{array}$ & $\begin{array}{c}19.9 \pm 2 \\
.3\end{array}$ & $\begin{array}{l}15.1- \\
24.7\end{array}$ & $\begin{array}{c}49.6 \pm 8 \\
.9\end{array}$ & $\begin{array}{c}30.8- \\
68.3\end{array}$ \\
\hline
\end{tabular}

\section{Correlation of vitamin D with visual}

\section{parameters according to age}

Vitamin D was determined to negatively correlate with IOP in patients below age 45 years of age ( $r-$ value: -0.803 ; p-value: 0.002). Vitamin D levels did not significantly correlate with IOP in patients from 45 to 60 years old or older than 60 years (Table 3 and Figure 2).

\section{Correlation of vitamin D with visual parameters according to OCT levels}

Vitamin D was found to negatively correlate with age (r-value: -0.526; p-value: 0.044) when OCT was higher than $94 \mu \mathrm{m}$. Vitamin $\mathrm{D}$ did not significantly correlate with age when OCT was less than $94 \mu \mathrm{m}$ (Table 4 and Figure 3).

\section{Correlation of visual parameters with vitamin}

$D$ according to VEP latency levels

Vitamin D negatively correlated with IOP (r-value: p-value: 0.036) when VEP latency was less than 100 msec. Vitamin D did not significantly correlate with IOP when VEP latency was greater than or equal to $100 \mathrm{msec}$ (Table 5 and Figure 4). 


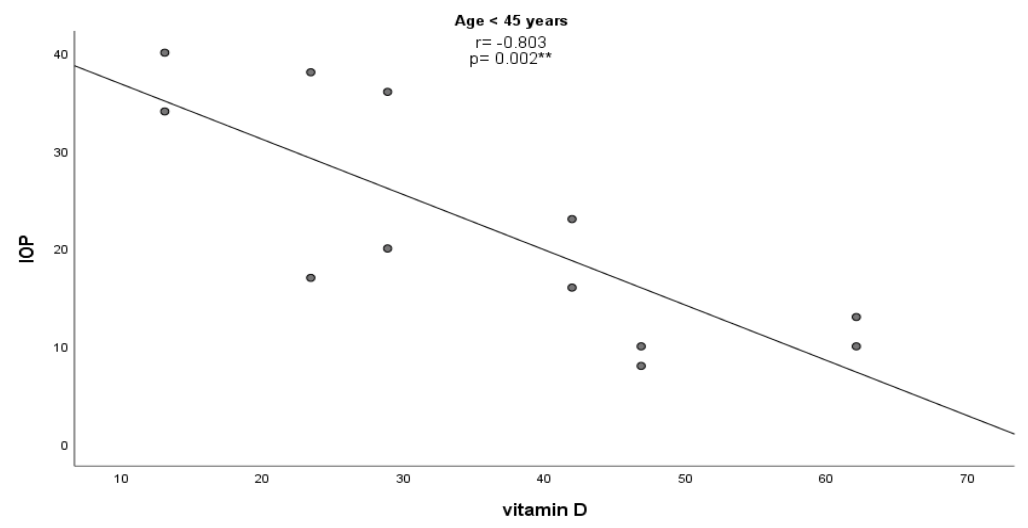

Figure 2: Correlation between vitamin D and IOP below age of 45years

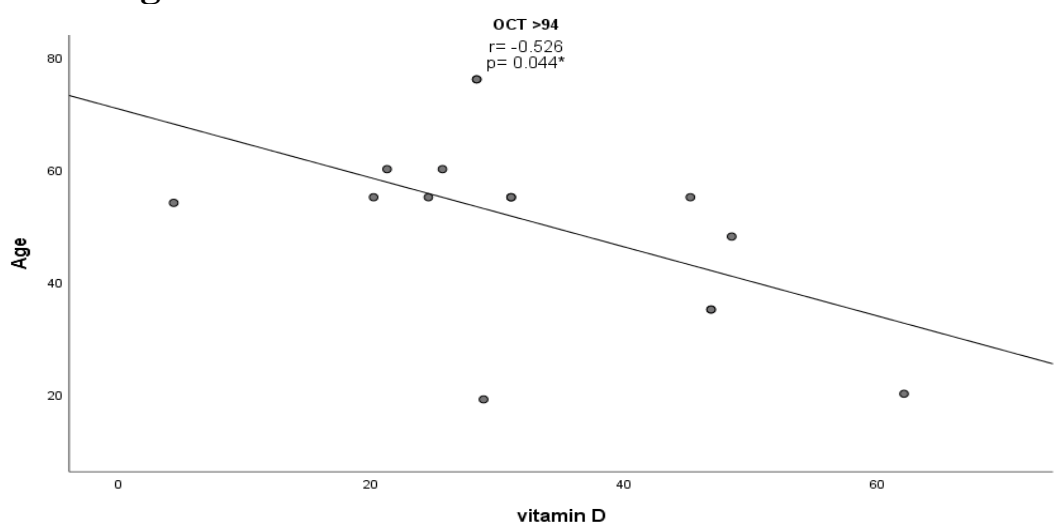

Figure 3: Correlation between vitamin D and age according to OCT values

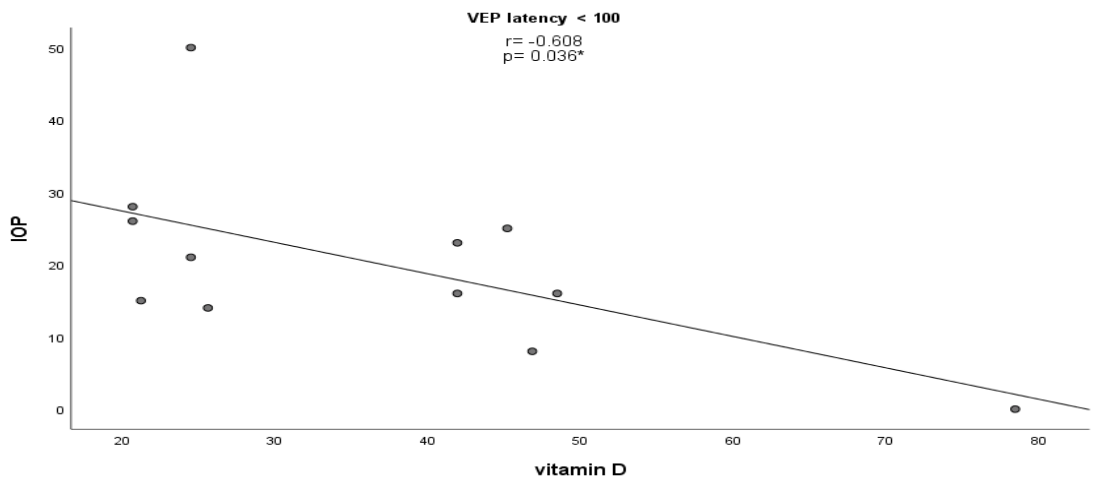

Figure 4: Correlation between vitamin D and IOP according to VEP latency levels

Table 3: Correlation according to Vitamin D (n=82) (VEP: Visual evoked potential; BCVA: Best corrected Visual Acuity; IOP: Intraocular pressure; OCT: Optical coherence tomography)

\begin{tabular}{|c|c|c|c|c|c|c|}
\hline & \multicolumn{6}{|c|}{ Vitamin D } \\
\hline & \multicolumn{2}{|c|}{$<45$ years } & \multicolumn{2}{|c|}{45 to 60 years } & \multicolumn{2}{|c|}{$>60$ years } \\
\hline & $\mathbf{r}$ & $\mathbf{p}$ & $\mathbf{r}$ & $\mathbf{p}$ & $\mathbf{r}$ & $\mathbf{p}$ \\
\hline VEP latency & -0.460 & 0.132 & 0.008 & 0.964 & -0.043 & 0.864 \\
\hline VEP latency levels $(1-<104,2-\geq 104)$ & 0.195 & 0.543 & -0.135 & 0.420 & -0.231 & 0.357 \\
\hline Amplitude & -0.235 & 0.462 & 0.182 & 0.273 & -0.402 & 0.098 \\
\hline BCVA & 0.416 & 0.178 & -0.070 & 0.678 & 0.113 & 0.655 \\
\hline IOP & -0.803 & $0.002 * *$ & -0.262 & 0.112 & 0.081 & 0.750 \\
\hline OCT & 0.440 & 0.152 & -0.138 & 0.409 & -0.003 & 0.991 \\
\hline
\end{tabular}


Table 4: Correlation with vitamin D according to OCT levels (n=82) (VEP: Visual evoked potential; BCVA: Best corrected Visual Acuity; IOP: Intraocular pressure; OCT: Optical coherence tomography)

\begin{tabular}{|l|c|c|c|c|}
\hline \multirow{2}{*}{} & \multicolumn{2}{|c|}{ Vitamin D } \\
\cline { 2 - 6 } & $\mathbf{2}$ & $\mathbf{3}$ & \multicolumn{3}{|c|}{ OCT >94 } \\
\cline { 2 - 6 } Age & -0.089 & 0.527 & $\mathbf{p}$ & $\mathbf{0 4}$ \\
\hline VEP latency & -0.082 & 0.526 & 0.557 & 0.576 \\
\hline Amplitude & 0.035 & 0.801 & 0.230 & 0.411 \\
\hline BCVA & 0.018 & 0.896 & -0.010 & 0.971 \\
\hline IOP & -0.260 & 0.060 & -0.374 & 0.169 \\
\hline
\end{tabular}

Table 5: Correlation with vitamin D according to VEP latency levels (n=82) (VEP: Visual evoked potential; BCVA: Best corrected Visual Acuity; IOP: Intraocular pressure; OCT: Optical coherence tomography)

\begin{tabular}{|c|c|c|c|c|}
\hline & \multicolumn{4}{|c|}{ Vitamin D } \\
\hline & \multicolumn{2}{|c|}{ VEP latency $<100$} & \multicolumn{2}{|c|}{ VEP latency $\geq 100$} \\
\hline & $\mathbf{r}$ & $\mathbf{p}$ & $\mathbf{r}$ & $\mathbf{p}$ \\
\hline Amplitude & 0.206 & 0.522 & -0.024 & 0.860 \\
\hline BCVA & -0.451 & 0.141 & 0.135 & 0.323 \\
\hline IOP & -0.608 & $0.036 *$ & -0.190 & 0.161 \\
\hline OCT & -0.350 & 0.265 & 0.033 & 0.807 \\
\hline
\end{tabular}

\section{DISCUSSION}

The role and function of vitamin $\mathrm{D}$ is not restricted to bone, as it also targets a larger number of nonbone organs, including the eye. Thus, serum vitamin D deficiency could be associated with visual function and retinal structure in older adults. Older adults are often unable to maintain normal vitamin D status. In this present study, vitamin D deficiency was associated with advancing age in patients with POAG. We also found that RNFL thickness progressively decreased with advancing age in patients with POAG. This result is in accordance with Beauchet et al. [14], who examined the association between visual function and serum 25OHD concentrations in a French community-dwelling population aged 65 years and older. Beauchet demonstrated that low serum 25OHD concentrations were associated with worse visual acuity. Vitamin $D$ is identified as a neurosteroid hormone involved in the trophic function of neural cells, as in the retina, and age-related D deficiency may contribute to cell degeneration.

Concerning the correlation of vitamin D with visual parameters, we found that vitamin D levels significantly and negatively correlated with IOP in patients younger than 45 years. In contrast, vitamin D levels did not correlate with IOP in older patients ( $>45$ years). Thus, vitamin D may play a role in the regulation of IOP. This result is in agreement with Krefting et al. [4] and Goncalves et al. [15], who showed that $1,25(\mathrm{OH})_{2} \mathrm{D}$ depressed the expression of several genes related to the regulation of IOP. In addition, Krefting and Goncalves found that topically applied vitamin D reduced IOP in non-human primates. These findings indicate a role for vitamin $\mathrm{D}$ in IOP regulation in humans. 
In this present study, vitamin D was significantly and negatively correlated with age when OCT (RNFL thickness) was greater than $94 \mu \mathrm{m}$. However, when OCT was less than $94 \mu \mathrm{m}$, vitamin $\mathrm{D}$ did not correlate with age. Thus, vitamin $\mathrm{D}$ is needed during aging to protect the rim of the optic disk and avoid damage and thinning of the RNFL. However, once damage occurs, the role of vitamin $\mathrm{D}$ is noted to decrease. This result is in agreement with Ocansey et al. [16], who observed that RNFL declines gradually as age increases, with a $0.25 \mu \mathrm{m}$ reduction in mean RNFL thickness per year. Similar findings were reported by Knight and colleagues [17], who showed a decrease of 0.38 $\mu \mathrm{m}$ per year using scanning laser polarimetry and $0.19 \mu \mathrm{m}$ per year using OCT. Mashige and Oduntan [18] demonstrated a $0.11 \mu \mathrm{m}$ per year rate of decline.

Vitamin D significantly and negatively correlated with IOP when VEP latency was less than 100 msec. However, when VEP latency was equal to or greater than $100 \mathrm{msec}$, vitamin D did not correlate with IOP. Thus, vitamin D has an ameliorating effect on IOP when the optic nerve conduction velocity is normal, but once optic nerve function starts deteriorating, the vitamin D effects decrease. This result was in agreement with Yoo and Hong [19], who suggested that vitamin D deficiency may be significantly linked to optic nerve dysfunction in patients with POAG, rather than only to occurring structural glaucomatous changes. Yoo and Hong demonstrated an insignificant increased risk of $\mathrm{OAG}$ in the highest quintile of serum 25OHD levels; in this group, OAG and vitamin D exhibited a significant quadratic association. Also,
Yoo and Hong demonstrated that the IOP cup-todisk ratios were significantly related to serum vitamin D levels. Thus, they suggested that low vitamin D levels are associated with an increased risk of OAG. Vitamin D deficiency should be considered as an independent risk factor for OAG. Low vitamin D levels might cause additional dangerous effects on the optic nerve, because patients with POAG already have impaired vision that might reduce daily activities and lead to lower vitamin D levels. Therefore, patients with POAG might be in a vicious cycle of visual impairment and low vitamin D levels [20].

\section{Conclusion}

This present study clarifies the neurophysiological role of vitamin D deficiency in POAG and the correlation between vitamin D deficiency and structural changes associated with POAG. Vitamin D may play a role in the regulation of intraocular pressure. During aging, the rim of the optic disc should be protected to avoid damage and thinning of the RNFL, but once damage takes place, the role of vitamin D also decreases. Also, vitamin D has an ameliorating effect on IOP when optic nerve conduction velocity is normal, but once optic nerve function deteriorates, the effects of vitamin $\mathrm{D}$ are noted to decrease.

\section{ETHICS APPROVAL AND CONSENT TO PARTICIPATE:}

The Ethics Committee of the Faculty of Medicine (Assiut University) and Assiut University Hospital approved this study. The procedure was discussed, and written informed consent was obtained from all patients. 


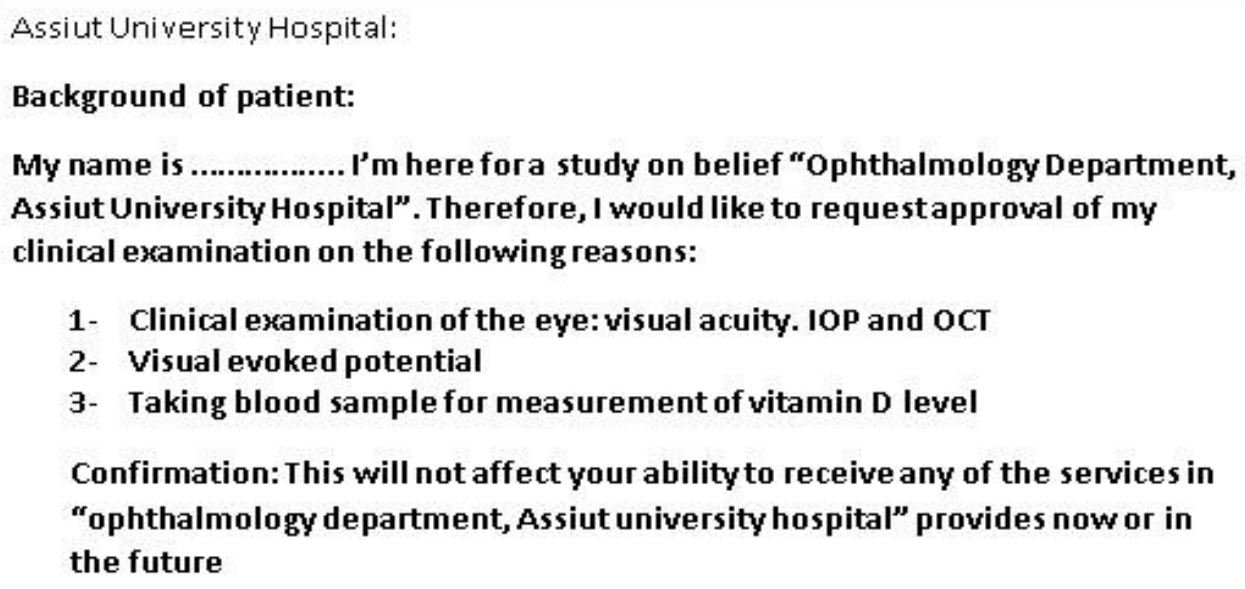

\section{AUTHORS' CONTRIBUTIONS:}

Fahmy,Hassan L.: recruitment of patients from the Department of Ophthalmology, Assiut University Hospital, Assiut, Egypt. Discusses the procedure, and takes written informed consent from all patients. Measures Best Corrected Visual Acuity and OCT to all patients.

Ali, Anwar M.: measures Visual Evoked Potential to all patients

Sayed, Sally A. (Corresponding Author): takes blood samples from all patients and measures serum 25-hydroxyvitamin D levels. Collects data from other authors, analyzes and interprets data, writes and submits the manuscript.

Anwar, Mohammed: measures intraocular pressure to all patients.

\section{FUNDING:}

The authors received no specific funding for this work.

\section{ACKNOWLEDGMENTS}

We acknowledge the nurses, residents, and staff who worked with Prof. Dr. Hassan L. Fahmy at the ophthalmology clinic and OCT unit in the Department of Ophthalmology, Assiut University
Hospital, Assiut, Egypt for their support during data collection and the use of the eye equipment.

\section{COMPETING INTERESTS}

The authors declare that there are no conflicts of interest regarding the publication of this paper.

\section{REFERENCES}

[1] Ayyagari R, Yii-der IC, Zangwill LM, et al. ADAGES III Genomics Study Group. Association of severity of primary openangle glaucoma with serum vitamin D levels in patients of African descent. Mol Vis 2019;25:438-445.

[2] Song YJ, Kim YK, Jeoung JW, et al. Assessment of open-angle glaucoma peripapillary and macular choroidal thickness using swept-source optical coherence tomography (SS-OCT). PLoS One 2016;11(6): 0157333.

[3] Jacquillet G, Unwin RJ. Physiological regulation of phosphate by vitamin D, parathyroid hormone (PTH) and phosphate (Pi). Pflugers Arch 2019;471(1):83-98.

[4] Krefting EA, Jorde R, Christoffersen T, et al. Vitamin D and intraocular pressureresults from a case-control and an intervention study. Acta Ophthalmol 
2014;92(4):345-349.

[5] Kocaturk T, Bekmez S, Unubol M. Effects of vitamin D deficiency on intraocular pressure values obtained by ocular response analyzer. Int Ophthalmol 2020;40(3):697-701.

[6] Dusso AS, Brown AJ, Slatopolsky E. Vitamin D. Am $J$ Physiol Renal Physiol 2005;289(1):8-28.

[7] Ashcroft SP, Bass JJ, Kazi AA, et al. The vitamin $\mathrm{D}$ receptor regulates mitochondrial function in $\mathrm{C} 2 \mathrm{C} 12$ myoblasts. Am J Physiol Cell Physiol 2020;318(3):C536-C541.

[8] Jha MK, Thakur D, Limbu N, et al. Visual evoked potentials in primary open angle glaucoma. J Neurodegener Dis 2017.

[9] Anguelov B, Petrova K. Diagnostic accuracy of the parameters from ganglion cell complex map, evaluated with SD-OCT in primary open-angle glaucoma. Ophthalmology in Russia, 2014;11(3):2832.

[10] Bhartiya S, Bali SJ, James M, et al. Test retest variability of TonoPen AVIA. Indian J Ophthalmol 2013;61(3):129-131.

[11] Firan AM, Iancu RC, Bujor IA, et al. The role of Visual Evoked Potential (VEP) in monitoring the progression and in guiding the treatment of glaucoma patients with poor compliance Rom $J$ Ophthalmol 2020;64(2):205-212.

[12] Kotowski J, Folio LS, Wollstein G, et al. Glaucoma discrimination of segmented cirrus spectral domain optical coherence tomography (SD-OCT) macular scans. $\mathrm{Br} J$ Ophthalmol 2012;96(11):1420-1425.

[13] Knutsen KV, Brekke M, Gjelstad S, et al. Vitamin D status in patients with musculoskeletal pain, fatigue and headache: a cross-sectional descriptive study in a multi-ethnic general practice in Norway. Scand J Prim Health Care Suppl 2010;28(3):166-171.

[14] Beauchet O, Milea D, Graffe A, et al. Association between serum 25-hydroxyvitamin D concentrations and vision: A cross-sectional population-based study of older adults. J Am Geriatr Soc 2011;59(3):568-570.

[15] Goncalves A, Milea D, Gohier P, et al. Serum vitamin D status is associated with the presence but not the severity of primary open angle glaucoma. Maturitas 2015;81(4):470-474.

[16] Ocansey S, Abu EK, Owusu-Ansah A, et al. Normative values of retinal nerve fibre layer thickness and optic nerve head parameters and their association with visual function in an African population. J Ophthal 2020.

[17] Knight OJ, Chang RT, Feuer WJ, et al. Comparison of retinal nerve fiber layer measurements using time domain and spectral domain optical coherent tomography.

Ophthalmology 2009;116(7):1271-1277.

[18] Mashige KP, Oduntan OA. Retinal nerve fibre layer thickness values and their associations with ocular and systemic parameters in Black South Africans. Afr Health Sci 2016;16(4):1188-1194.

[19] Yoo TK, Hong S. Is vitamin D status associated with open-angle glaucoma? A cross-sectional study from South Korea. Public Health Nutr 2014;17(4):833-843.

[20] McKinnon SJ. The cell and molecular 
biology of glaucoma: common neurodegenerative pathways and relevance

to glaucoma. Invest Ophthalmol Vis Sci 2012;53(5):2485-2487. 